\title{
EL VIGNOLA DEL COLEGIO DE ARQUITECTOS DE VALENCIA Y SUS RETABLOS DE TRAZA SEVILLANA: JUAN MARTÍNEZ MONTAÑÉS
}

\author{
POR \\ BENITO NAVARRETE PRIETO \\ Universidad de Alcalá
}

Presentamos un análisis de tres de los dibujos de retablos que se conservan en el ejemplar del Vignola del Colegio de Arquitectos de Valencia y que pertenecen al escultor sevillano Juan Martínez Montañés. El primero de ellos es preparatorio para el retablo de la Inmaculada de la iglesia parroquial del Pedroso (Sevi1la), conservado in situ actualmente. El segundo es para el perdido Retablo de los dominicos de Portacoeli de Sevilla, del que se conserva el Santo Domingo de Guzmán azotándose en el Museo de Bellas Artes de Sevilla, y el tercero es modelo para la tipología del Montañés del Retablo-Tabernáculo en la iglesia del convento de Santa Clara de Sevilla, estudiándose además el origen de algunos elementos de Montañés en los propios grabados del libro de Vignola.

Palabras clave: Vignola; Martínez Montañés; escultura española; s. XVII.

Three drawings of altarpieces executed by the Sevillian sculptor Juan Martínez Montañés, preserved in the copy of Vignola's architectural treatise in the Colegio de Arquitectos de Valencia are analyzed here. The first drawing is a preliminary study for the altarpiece of the Immaculate Conception in the Parrochial Church of El Pedroso (Seville). The second drawing, also a preliminary idea, is for the lost altarpiece of the Dominican monastery of Portacelli in Seville, from which only the figure of St Dominic of Guzman flagellating himself has survived (Museo de Bellas Artes de Sevilla). The third is the model for the type of altarpiece-tabernacle used by Montañes in the Convent of Santa Clara (Seville). The author also points out the origin of certain elements of Montañes's designs in the prints of Vignola's treatise.

Key words: Vignola; Martínez Montañés; Spanish sculpture; seventeenth century.

En 1996, fruto de nuestro paso por la Universidad de Valencia, tuvimos ocasión de estudiar y publicar, junto al profesor Pérez Sánchez ${ }^{1}$ un interesante conjunto de dibujos de Francisco de Herrera el Viejo, preparatorios para las yeserías de la Iglesia del colegio de San Buenaventura de Sevilla, que suministraban, además, el alzado y despiece de las arcadas y marcos donde posteriormente se encastraría el ciclo que realizara este pintor conjuntamente con Francisco de Zurbarán. Estos dibujos se encontraban pegados e intercalados en la edición príncipe de 1562 de Iacomo Barozzio da Vignola, Regola delli cinque ordini d'architettura ${ }^{2}$. En aque-

\footnotetext{
${ }^{1}$ Pérez Sánchez, A.E. y Navarrete Prieto, B., «Sobre Herrera el Viejo» en Archivo Español de Arte, 276, 1996, pp. 365-387.

${ }^{2}$ A pesar del estudio científico e identificación que hicimos en su momento, estos dibujos de Francisco de Herrera han seguido ignorándose, incluso desconociéndose nuestro artículo por los encargados de la edición facsimilar del ejemplar $\mathbf{R}$ 103 conservado en la Biblioteca del Colegio de Arquitectos de Valencia, para quienes estos dibujos pasan completamente
} 

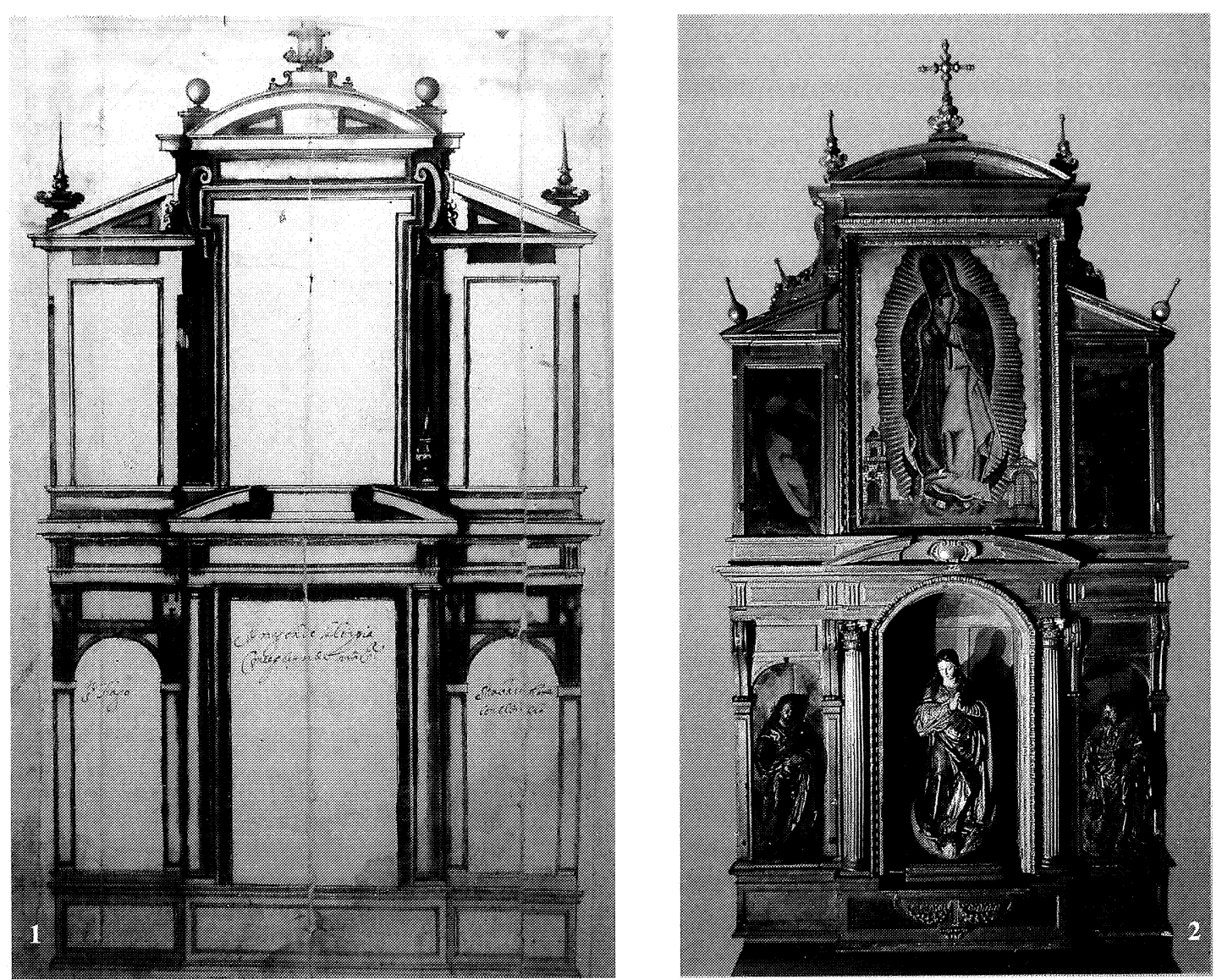

Fig. 1. Juan Martínez Montañés, dibujo preparatorio para el Retablo de la Inmaculada de la Iglesia Parroquial del Pedroso (Sevilla). Adherido al ejemplar del Vignola, Colegio de Arquitectos de Valencia.

Fig. 2. Juan Martínez Montañés, Retablo de la Inmaculada, Iglesia Parroquial del Pedroso, Sevilla.

llas fechas ya señalábamos la autoría sevillana para los demás diseños, resaltando la importancia de este ejemplar misceláneo, sin duda instrumento de trabajo de un artista, tracista de retablos o arquitecto, pues además de los diseños se incluyen un conjunto de estampas de Vredeman de Vries sobre fondos arquitectónicos y fuentes ${ }^{3}$, otras estampas de tabernáculos, túmulos funerarios y grabados de edificios romanos y florentinos, obras de Miguel Ángel, e intercalados entre las láminas del Vignola, grabados del propio Francisco de Herrera entre los que se encuentran: la portada de los Comentarii in Summam Theologiae S. Thomae de $1623^{4}$, la rara estampa del Patronato de la Orden Trinitaria de 1627, de la que, como señalamos en la otra ocasión, sólo se conocía el ejemplar de la Biblioteca Nacional de Madrid ${ }^{5}$ y una prueba de

inadvertidos. Cfr. Sellés Cantos, P., «Apunte para la historia editorial de la Regola delli cinque ordini d'architettura di M. Iacomo Barozzio da Vignola» en Regola delli cinque ordini d'architettura di M. Iacomo Barozzio da Vignola, Reproducción del libro R. 103 de la Biblioteca del Colegio Territorial de Arquitectos de Valencia, Editorial de la Universidad Politécnica de Valencia, Valencia, 2002.

${ }^{3}$ No hay que olvidar la importancia que tienen las estampas de Vredeman de Vries presentes en las bibliotecas sevillanas y en los fondos arquitectónicos de la pintura sevillana, concretamente en Zurbarán para su Apoteosis de Santo Tomás de Aquino tal y como dejamos sentado en nuestra tesis doctoral: La Pintura Andaluza del siglo XVII y sus fuentes grabadas, Fundación de Apoyo a la Historia del Arte Hispánico, Madrid, 1998, pp. 229-230

${ }^{4}$ Sobre esta estampa véase la ficha catalográfica del Profesor Martínez Ripoll en Velázquez y Sevilla, cat. exp., Junta de Andalucía, Sevilla, 1999, pp. 112-113, nº 49.

${ }_{5}^{5}$ Véase reproducido y estudiado en el libro de Martínez Ripoll, A., Francisco de Herrera el Viejo, Sevilla, 1978, p. 247, $\mathrm{n}^{\circ} \mathrm{G} 3$ y G4, figs. 6 y 7 .

AEA, LXXVIII, 2005, 311, pp. 235 a 244 
estado de la portada del libro Novus Index Librorum Prohibitorum del Cardenal Zapata que fue dibujada por el hermano del pintor, Juan de Herrera. Como se aprecia la selección de obras relacionadas con Herrera inclina a pensar en la posibilidad de que el ejemplar valenciano hubiera sido el libro de trabajo del propio artista.

Lo cierto es que tanto las trazas de San Buenaventura, las estampas citadas más arriba, y los dibujos de los retablos, están muy en relación con algunas de las láminas del Vignola, lo que indudablemente inclina a pensar en este libro como el lugar donde se hallaba el material de trabajo del artista, y en definitiva, en una fábrica de ingenios. No en balde la tratadística renacentista: Palladio, Serlio y ahora Vignola ${ }^{6}$ fueron elemento recurrente de nuestros tracistas de retablos, como dejó sentado hace años el profesor Palomero ${ }^{7}$. Por otra parte el seguimiento de Vignola ${ }^{8}$ por parte de los tracistas de retablos sevillanos se manifiesta de manera absoluta en los diseños que fueron publicados por Sancho Corbacho, aunque más tardíos que los nuestros ${ }^{9}$.

Podemos ahora, tras un detenido análisis de los dibujos conservados en este importante libro, y gracias a la edición facsimilar del mismo, acercarnos a la autoría de dos de los retablos y adelantar la de un tercero de los dieciocho que se conservan entre las láminas vignolescas.

El primero de ellos se encuentra adherido al folio (9v) (Fig. 1) y presenta un diseño de retablo de porte enteramente clasicista de dos cuerpos y con doble frontón como remate, recto y curvo ${ }^{10}$, con tres calles en los dos cuerpos, contando el primer cuerpo con un remate de frontón recto roto en el que se deja espacio para un motivo dentro de un cabecero o dintel vacío . A los lados de las calles laterales del primer cuerpo sendas pilastras de clarísima filiación vignolesca y sobre las hornacinas el correspondiente cabecero o dintel. Flanqueando el cajeado del segundo cuerpo dos jarras rematadas con agujas delante de unas pilastras. Este cuerpo, presenta en el recuadro de su calle central el seguimiento directo de la lámina 41 que acompaña a la edición del Vignola y fue añadida ${ }^{11}$, manteniendo el dibujo incluso el ritmo quebrado para el marco de la parte superior. Las calles laterales quedan rematadas por dos jarras terminadas en agujas y el frontón curvo con que termina la calle central, con sendas bolas a modo de ático y, al centro, la peana de lo que sería el asiento de la cruz como coronamiento. Este frontón curvo está tomado de una de las láminas de una ventana correspondiente a la Biblioteca Laurenziana de Miguel Ángel ${ }^{12}$.

\footnotetext{
${ }^{6}$ Los ejemplos en los que se cita a Vignola como modelo en la retablística sevillana son frecuentes. Podemos destacar el del contrato del 15 de febrero de 1630, donde el ensamblador Jerónimo Velázquez se comprometía a emplear en el primer cuerpo del retablo mayor de la iglesia conventual de San José del Carmen de Sevilla «La orden corintina, guardando el rigor del arte en todos sus miembros como los dispone Viñola» en Documentos para la Historia del Arte en Andalucía, II, Sevilla, 1930, p. 297.

${ }^{7}$ Palomero Páramo, J.Ma ; «El Retablo como laboratorio de ideas» en Revista de Arte Sevillano, 1, 1982, pp. 56 y 57 y del mismo autor; «La influencia de los tratados arquitectónicos de Serlio y Palladio en los retablos de Martínez Montañés» en Homenaje al Prof. Dr. Hernández Díaz, T. I, Sevilla, 1982, pp. 503-525; El Retablo Sevillano del Renacimiento: Análisis y Evolución 1560-1629, Diputación Provincial de Sevilla, 1983. Estos trabajos podemos considerarlos pioneros en el estudio de las fuentes para la arquitectura retablística. Véase recientemente para dibujos de arquitectura; Fernández Martín, M Ma., Dibujos sevillanos de Arquitectura de la primera mitad del siglo XVII, Universidad de Sevilla, 2003. Véase también la ficha de Francisco Javier Herrera sobre las «Trazas para el retablo mayor del Convento de Sta. M. ${ }^{a}$ de Gracia de Sevilla» en cat. exp. 1999, op. cit., pp. 150-151, n. ${ }^{\circ} 68$.

${ }^{8}$ Palomero Páramo presenta la secuencia de seguimiento de los tratados arquitectónicos en Sevilla del siguiente modo: Bramante-Serlio-Palladio-Vignola. Cfr. Palomero Páramo, J.M., Opus Cit., 1983, p. 90.

${ }^{9}$ Sancho Corbacho, A., Dibujos Arquitectónicos del siglo XVII. Una colección inédita de 1663, Sevilla, 1947.

${ }^{10}$ Palomero Páramo vincula este doble frontón con soluciones de Bramante para Santa María presso San Satiro y, sobre todo, con el grabado del Libro Quarto de Palladio del templo romano de la Paz. Cfr. Palomero Páramo, J., Opus Cit., 1982, p. 524.

${ }^{11}$ Esta lámina corresponde al folio $78 \mathrm{r}$ y reproduce una de las puertas del Campidoglio realizada por Miguel Ángel. Estas estampas se encuentran añadidas en casi todas las ediciones del Vignola. El ritmo quebrado que aparece en algunos retablos montañesinos de esta época, rompiendo la traza rectangular por la parte superior y ensanchándola, depende por tanto, de este modelo miguelangelesco y su fuente se halla en esta estampa.

${ }^{12}$ Folio $86 \mathrm{r}$ del ejemplar del Vignola que estudiamos.
} 
Las identificaciones de los asuntos que habían de ir en el primer cuerpo señalan en la calle central: «Ymagen de la limpia Concepción de $\mathrm{m}^{\mathrm{a}} \mathrm{S}^{\mathrm{a}}$ »; en las calles laterales, a la derecha del espectador: «San Bartolomé con el diablo» y a la izquierda, «Santiago».

En el segundo cuerpo no tenemos indicación alguna del asunto, sin duda porque en el retablo para el que serviría este dibujo ya existía un antiguo relieve de Santa Catalina, perteneciente a un antiguo retablo y que Montañés se obligaba en el concierto del retablo a restaurar y acomodar ${ }^{13}$. Se trata, sin duda alguna, del dibujo preparatorio para el Retablo de la Inmacula$d a$ de la Iglesia Parroquial del Pedroso de Sevilla (Fig. 2), una de las obras tempranas de Martínez Montañés y más serenas y limpias de ejecución, contratado el 9 de mayo de 1606 en unión de Francisco Pacheco, terminado en 1608 y finiquitado en $1609^{14}$.

Interesa señalar las variaciones con respecto a la traza del dibujo original ahora identificado. En primer lugar la modificación de la caja del primer cuerpo donde se encuentra la Inmaculada, recta en el diseño y curva, a modo de hornacina en el retablo. Por otro lado el frontón roto, levemente curvado del primer cuerpo, aparece limpio en el diseño y con una cartela o espejo centrado en el tímpano en el retablo y en el segundo cuerpo, a los lados del tema central en el diseño, aparecen sendas volutas que quedan eliminadas en el retablo que presenta una decoración de gallones enmarcando la pintura de la Virgen de Guadalupe que sustituiría al relieve de la Santa Catalina anterior. A derecha e izquierda en el retablo aparecen dos pinturas de San Diego de Alcalá y San Pedro. A los lados del ático unas macollas de frutas se dejan caer levemente sugeridas, apareciendo éstas en el diseño al lado de las volutas.

En el banco del retablo aparece un encuadramiento con un texto indicando la fecha de conclusión del mismo: «Acabóse este retablo año de 1608 siendo capellán perpetuo de la capellanía Bartolomé de Morales Racionero de la Santa Iglesia de Osuna. Fundola Diego Pérez Clérigo».

Como señaló Gilman Proske el retablo del Pedroso es un ejemplo de retablo en el que Montañés está todavía imbuido del estilo desornamentado, ese clasicismo postescurialense que se manifiesta palpablemente en las trazas del dibujo y que, en la realización, intenta animar un poco con elementos no presentes, pero que indudablemente modernizan el rasguño inicial. No deja de ser sintomático, en este sentido, la alteración de los remates del último cuerpo. Las bolas de tradición escurialense desaparecen y son sustituidas por los pináculos situados en el dibujo en un nivel inferior. Este proceso de paulatina barroquización en el arte de Montañés confiere una mayor importancia a estos diseños que se constituyen en campo de experimentación.

Otro tema que puede resultar problemático es el de la paternidad de los diseños. Al aparecer Montañés y Pacheco contratando el retablo, es obligado pensar que la escultura y mazonería corrieran a cargo de Montañés y que Pacheco se limitara a estofar y encarnar las imágenes. A favor de esto tenemos la defensa que hace Pacheco en su Arte de la Pintura ${ }^{15}$ de los pintores encarnadores y de la intima amistad que unió al pintor y al escultor en sus primeros años y el posterior distanciamiento, tras la publicación en 1622 del opúsculo A los Profesores del Arte

\footnotetext{
${ }^{13}$ El relieve fue sustituido en fecha que desconocemos por una pintura de La Virgen de Guadalupe que es la que se encuentra en la actualidad en el retablo. Según Palomero Páramo es del siglo XVIII. Cfr. Palomero Páramo, J.M., Opus Cit., 1983, p. 410.

${ }^{14}$ Se viene citando que el contrato fue publicado por López Martínez, C., «Montañés y Pacheco en el Pedroso» en $E l$ Liberal, 15-1-1935. A pesar de que se sigue mencionando la publicación de este contrato en esta fecha en El Liberal, nosotros no la hemos encontrado en la revisión que hicimos en la hemeroteca de Sevilla, por lo que pensamos que esté en otro día y que la fecha esté equivocada. La carta de pago y finiquito en Documentos para la Historia del Arte en Andalucía, V, 1933, pp. 55-56. Véase posteriormente: Gilman Proske, B., Juan Martínez Montañés Sevillian Sculptor, The Hispanic Society of América, New York, 1967, pp. 47-48; Palomero Páramo, Opus Cit., 1983, fig. 113; Hernández Díaz, J., Juan Martínez Montañés (1568-1649), Guadalquivir, Sevilla, 1987, p. 124.

${ }^{15}$ Pacheco, F., Arte de la Pintura, Edición crítica de Bonaventura Bassegoda i Hugas, Cátedra, Madrid, p. 490. Véase especialmente las consideraciones que hace Bassegoda al comienzo del capítulo VI.
}

$A E A$, LXXVIII, 2005, 311, pp. 235 a 244 
de la Pintura ${ }^{16}$ que iba dirigido precisamente contra Juan Martínez Montañés, y causado por el litigio profesional entre los pintores encarnadores y los escultores.

Nos inclinamos, por tanto, a pensar que la traza de este retablo la diera Montañés ${ }^{17}$, de ser así, sería uno de los primeros dibujos que se dan a conocer del maestro, junto con los que a continuación presentamos, pues atribuible a él se conocía únicamente una Asunción de la Virgen ${ }^{18}$ preparatorio para uno de los relieves de la Iglesia de la Magdalena de Sevilla y perteneciente al Album Alcubierre (n. $\left.{ }^{\circ} 39\right)$, actualmente en la colección de don Juan Abelló. Ciertamente algunos de los angelillos que aparecen ascendiendo a la Virgen se relacionan en factura a alguno de los que aparecen en los dibujos de retablos insertados en el ejemplar de Vignola que ahora estudiamos.

La siguiente traza de retablo localizada pertenece al perdido Retablo mayor del Monasterio de Santo Domingo de Portacoeli de Sevilla, y la identificación ha sido posible gracias, nuevamente, a la indicación de los asuntos y a las esculturas de este retablo que se han conservado, o de las que ha quedado documento gráfico, además, por supuesto, de la descripción que nos hace Antonio Ponz en su Viaje de España, quien no duda en calificar al retablo de Portacoeli como «de los de mejor arquitectura que hay aquí» ${ }^{19}$. Por otra parte Ponz fue quien describió el retablo completamente antes de su desmembración, coincidiendo la descripción del viajero con las anotaciones que presenta nuestro dibujo y que a continuación exponemos.

Corresponde el dibujo al folio (10 v) del libro estudiado (Fig. 3) y contiene además una serie de elementos fundamentales para entender el posterior desarrollo de algunos de los detalles decorativos propios de Martínez Montañes, como serán la guirnalda de laurel a modo de friso y con una cinta cruzada al centro. Aunque estamos en unas fechas parecidas al anterior retablo del Pedroso, la evolución estética es notoria, presentando este de Portacoeli, merced al diseño ahora identificado, una mayor complicación.

El retablo fue contratado un año antes que el del Pedroso en 1605, otorgándose el finiquito de ambos en el mismo año de $1609^{20}$. Desgraciadamente esta obra pereció en 1835 dispersándose la imaginería, lo que hace que nuestro diseño cobre ahora una mayor relevancia como testimonio de lo desaparecido y para poder reconstruir el conjunto ${ }^{21}$ (Fig. 4). Lo que quedaba claro, tras la publicación del contrato, es que Francisco Pacheco se obligaba a dorar de oro limpio el retablo ajustado desde el sotabanco hasta el último remate, y a pintar al óleo las figuras y retratos que el patrono le pidiese y Martínez Montañés se encargaba de la parte arquitectónica, de la talla y escultura del retablo ${ }^{22}$. Como decíamos más arriba, nuevamente, las anotaciones del autor de la traza de los asuntos que irían en la calle principal son las que nos han hecho relacionar el dibujo con el retablo de Portacoeli:

\footnotetext{
${ }^{16}$ Véase publicado por Calvo Serraller, F., Teoría de la Pintura del Siglo de Oro, Madrid, 1981, pp. $180-191$.

${ }^{17}$ A favor de la autoría de Montañés de la traza del retablo está que en la carta de pago entre el escultor y el comitente Gonzalo de Morales, recibe 6.380 reales de plata de a treinta y cuatro maravedis cada uno «los cuales son de la hechura y pintura y llevada y asiento que yo hice para un altar de la Iglesia de la villa del Pedroso». Cfr. Documentos para la Historia del Arte en Andalucía, Laboratorio de Arte, Sevilla, 1933, p. 56.

${ }^{18}$ Véase reproducido y estudiado en Angulo, D. y Pérez Sánchez, A.E., A Corpus of Spanish Drawings, volume three. Seville School 1600 to 1650 , Harvey Miller, Londres, 1985, $\mathrm{n}^{\circ} 91$.

${ }^{19}$ Ponz, A., Viaje de España, ed. Aguilar, Madrid, 1947, p. 798.

${ }^{20}$ López Martínez, C., «Montañés y Pacheco en Santo Domingo de Portacoeli» en El Liberal, n 12.777; 8-12-1934 y del mismo periódico el correspondiente al $\mathrm{n}^{\circ} 12.781$ del Jueves 13-XII-1934, donde López Martínez da cuenta de la escritura de concierto en la que se describen los asuntos tal y como aparecen en nuestro dibujo. Únicamente se cambian los relieves de los lados del Sagrario. San Pedro y San Pablo en el contrato y Santo Tomás y San Pedro mártir en el dibujo. Véase también Palomero Páramo, J., Opus Cit., 1983, p. 393, fig. 107 donde hace también una reconstrucción del presente retablo. La asignación de los asuntos en las calles laterales queda alterada en Palomero con respecto al concierto que publica López Martínez así como a la ordenación que le asigna Ponz y a nuestro diseño. Sin embargo en la reconstrucción de Palomero los asuntos de la calle central son los correctos.

${ }^{21}$ Agradezco a Roberto Alonso Moral y Pedro Navarrete Prieto su ayuda en la confección del fotomontaje que reproducimos.

${ }^{22}$ López Martínez, C., Art. Cit. en El Liberal, nº 12.777 8-XII-1934
}

$A E A$, LXXVIII, 2005, 311, pp. 235 a 244 

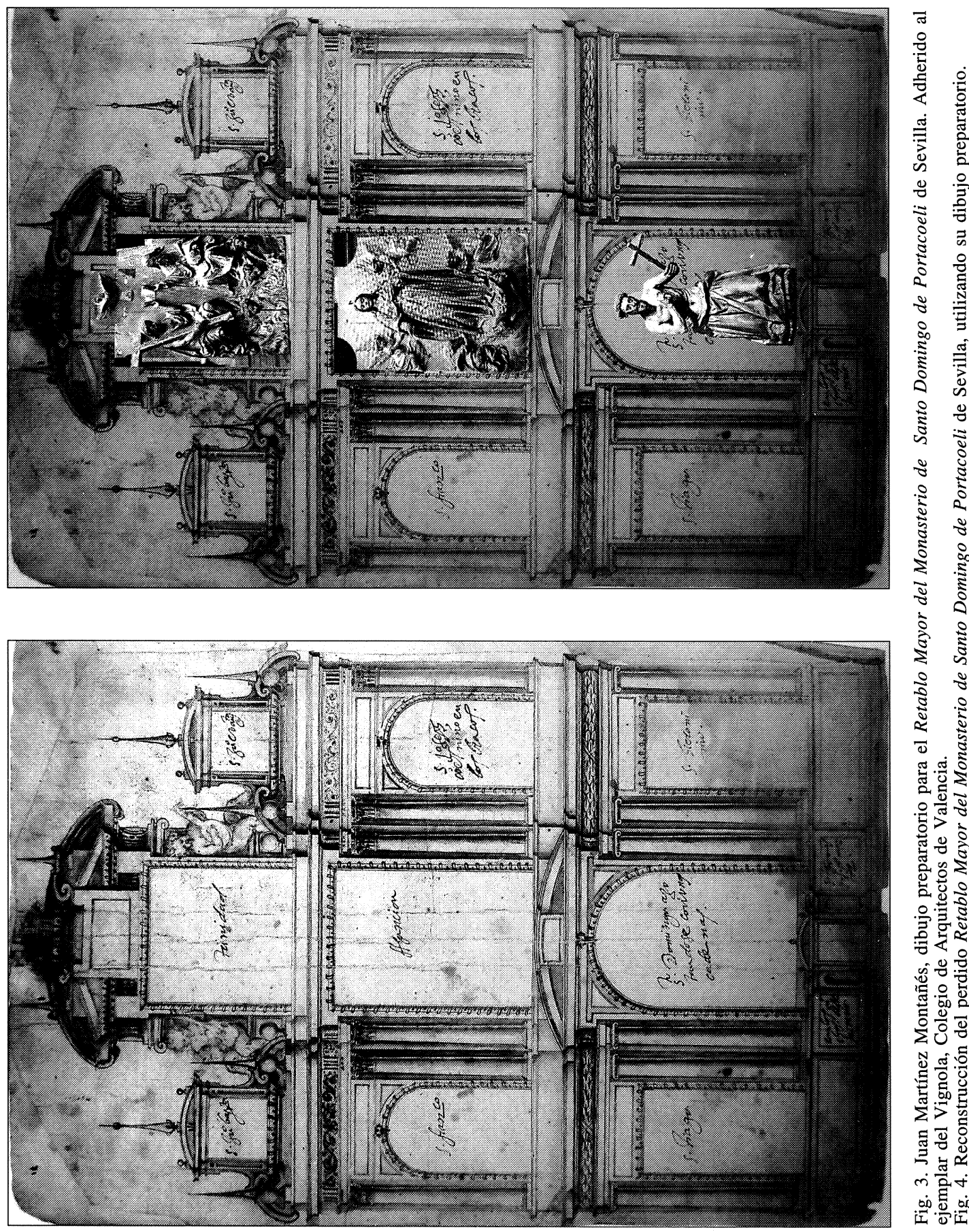

玒察玒 
Consta el dibujo del retablo de tres cuerpos y un pequeño ático rematado por un frontón curvo que contiene unas volutas y un frontón recto con un cabecero rectangular al centro, probablemente para disponer un relieve no identificado o para el remate de la Trinidad con la Paloma del Espíritu Santo. Descansan entre el segundo cuerpo y el tercero dos angelillos que tocan, uno elviolín y el otro la vihuela. La calle central presenta en el primer cuerpo, rematado en medio punto, el encajonamiento u hornacina y un frontón curvo con cabecero. En este nicho se situaba la escultura de Santo Domingo azotándose con unas cadenas, tal y como se anota en el diseño, obra maestra de Montañés conservada hoy día en el Museo de Bellas Artes de Sevilla e imagen titular del retablo que fue encarnado por Pacheco y de la que se sentía particularmente orgulloso en su Arte de la Pintura ${ }^{23}$. En el segundo cuerpo iría en el encuadramiento, según dice el dibujo, el relieve de la Asunción de la Virgen que estuvo un tiempo en la iglesia de San Bernardo de Sevilla, hasta que fue destruida en 1936, al igual que La Trinidad que coronaba el ático y que también aparece anotada en el dibujo del retablo y que conocemos gracias a los antiguas fotografías reproducidas por Hernández Díaz ${ }^{24}$. Es verdaderamente emocionante comprobar que lo, aparentemente efímero y frágil como es el dibujo, permanezca, y lo contundente y sólido como es la escultura, haya desaparecido pasto del vandalismo en 1936. Los demás asuntos que aparecen en el retablo no los hemos podido encontrar, probablemente porque se destruirían tras la desmembración del retablo en 1835. En la calle lateral derecha, según miraba el espectador, se hallaba en el primer cuerpo San Jerónimo, en el segundo cuerpo San José con el Niño en brazos y, en el ático, la imagen de San Juan Evangelista. En la calle lateral izquierda se hallaba Santiago en el primer cuerpo, San Francisco en el segundo y en el ático San Juan Bautista. Todos estos relieves estarían policromados por Francisco Pacheco.

El primer cuerpo presentaba el orden jónico con columnas pareadas enmarcando la calle central, ritmo que se mantiene en el segundo pero utilizando el orden corintio. Como remates vuelven a aparecer en el diseño las bolas escurialenses rematadas por pirámides y las agujas. El friso del primer cuerpo ostenta el característico motivo montañesino de la guirnalda de laurel con lazo que volverá a aparecer años después rematando la imagen titular de los RetablosTabernáculo del Convento de Santa Clara de Sevilla dedicados a los santos Juanes (Fig. 5 y 6). En el friso del segundo cuerpo aparece en el dibujo un motivo vegetal que, suponemos, iría pintado o esgrafiado.

Una última inscripción figura en el banco del retablo, a un lado y otro del tabernáculo, que nos informa de las imágenes que había en las dos pequeñas hornacinas del sagrario: «En los nichos desse sacrario Santo Thomas y San Pedro martir».

Tanto el dibujo anterior del Pedroso como este preparatorio para la traza de Portacoeli habría que vincularlos con los diseños que se les presentaban a los comitentes - González de Mendoza en el caso del retablo dominico - antes de la ejecución de los mismos, y por tanto, tienen un valor precioso al presentar la primera idea que, como hemos visto, se lleva luego a término.

Elementos decisivamente vignolescos y que han sido tomados por Martínez Montañés del citado libro de la Regola delli cinque ordini son los remates de frontones con volutas, sobre las que descansan unos «putti», unas veces tocando trompetas como ocurre en el segundo cuerpo del retablo mayor del Convento de Santa Clara de Sevilla (Fig. 7) y otras simplemente portando escudos ovalados con volutas. Esta solución la apreciamos, tanto en el remate del segundo cuerpo del retablo de San Isidoro del Campo, como en el primer cuerpo del retablo mayor de San Lorenzo de Sevilla (Fig. 8).

\footnotetext{
${ }^{23}$ Pacheco, F. Opus Cit., ed. Bassegoda, 1990, p. 498.

${ }^{24}$ Hernández Díaz, J., Martínez Montañés en «Artistas Andaluces», Laboratorio de Arte, Universidad de Sevilla, 1949 , Lám XVI, fig. 16 y 17 y Opus cit., 1987, pp. 114-115. Reproducidas y estudiadas también por Proske, 1967, Lám. 20-22.
} 

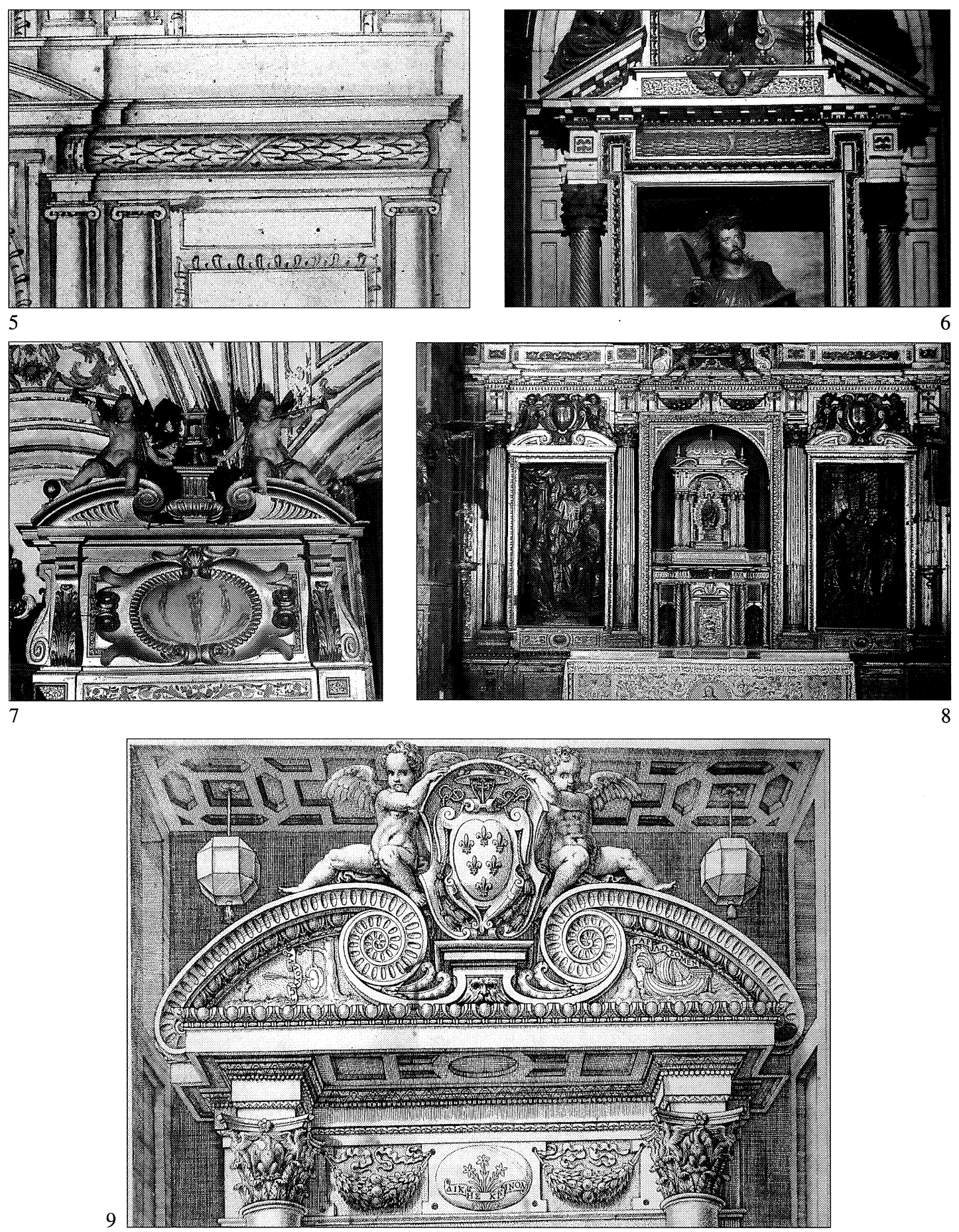

Fig. 5. Juan Martínez Montañés, detalle del friso del primer cuerpo del dibujo del Retablo Mayor del Monasterio de Santo Domingo de Portacoeli de Sevilla.

Fig. 6. Juan Martínez Montañés, detalle del friso del Retablo Tabernáculo de San Juan Evangelista, Convento de Santa Clara de Sevilla.

Fig. 7. Juan Martínez Montañés, detalle del remate de los frontones del segundo cuerpo del Retablo Mayor de Santa Clara de Sevilla.

Fig. 8. Juan Martínez Montañés, detalle del remate de los frontones del primer cuerpo del Retablo Mayor de San Lorenzo de Sevilla.

Fig. 9. Frontispicio del libro de Vignola, Regola delli cinque ordini d'architettura.

AEA, LXXVIII, 2005, 311, pp. 235 a 244 


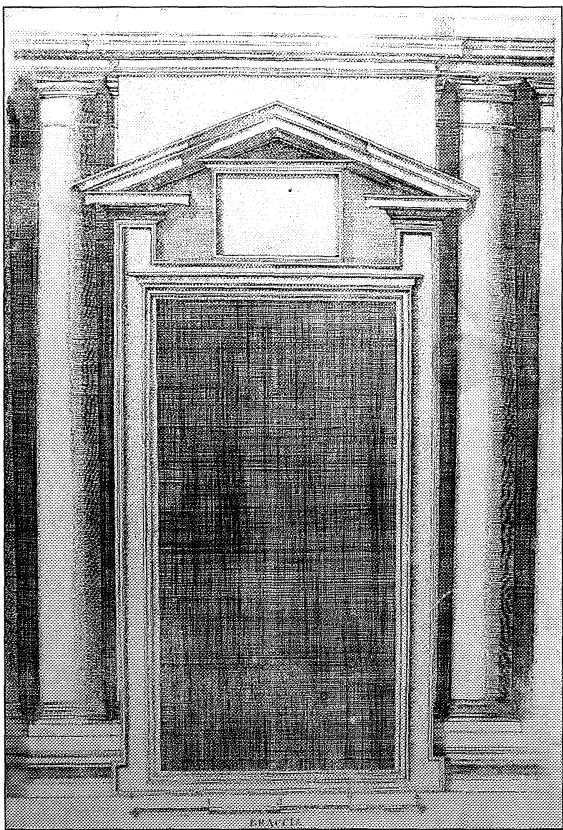

11
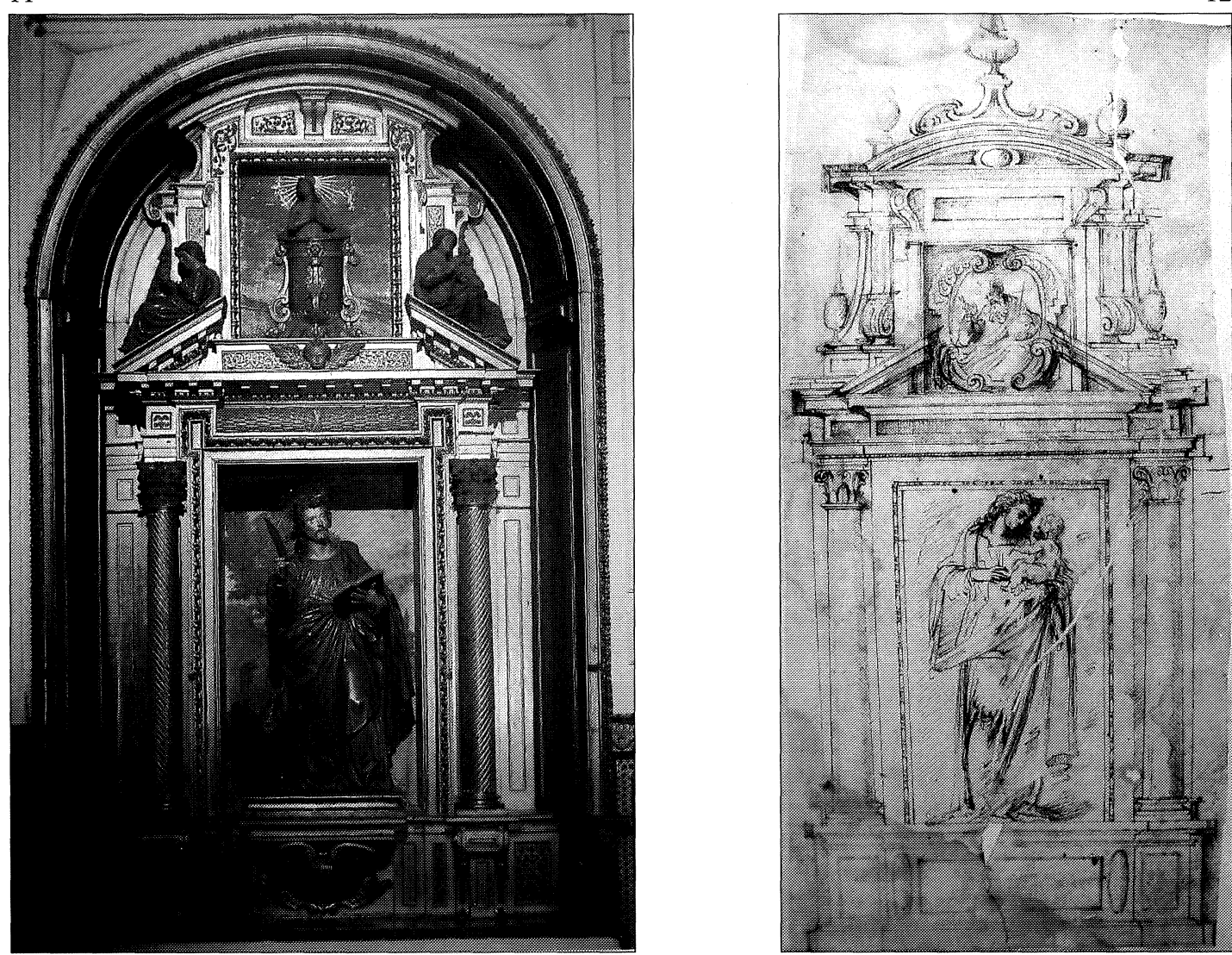

Fig. 10. Puerta de entrada a la Biblioteca Laurenziana de Miguel Ángel, grabado añadido a la edición del Vignola de 1562. Fig. 11. Juan Martínez Montañés, Retablo Tabernáculo de San Juan Evangelista, Convento de Santa Clara de Sevilla. Fig. 12. ¿Juan Martínez Montañés?, dibujo preparatorio para un Retablo Tabernáculo, Adherido al ejemplar del Vignola del Colegio de Arquitectos de Valencia.

AEA, LXXVIII, 2005, 311, pp. 235 a 244 
El origen de esta fórmula iconográfica está en el frontispicio del libro de Vignola (Fig. 9) en el que aparece el retrato del arquitecto coronado precisamente por el frontón curvo con volutas y los «putti» portando un escudo que empleara Montañés en las citadas obras. Esta solución no permaneció ajena a los artistas del momento, pues vuelve a utilizarla el mismo Francisco Pacheco en los remates de los encuadramientos que presentan a los retratados en el Libro de Retratos de Ilustres y Memorables Varones. Estamos pues, nuevamente, ante la fuente común de una fórmula que haría fortuna en la retablística sevillana.

La tipología del Retablo-Tabernáculo y su filiación miguelangelesca: La Biblioteca Laurenziana como modelo

Una de las tipologías más características estudiadas tanto por Hernández Díaz como por Palomero Páramo es la del Retablo-Tabernáculo, puesto en práctica por Jerónimo Hernández . De este escultor se conserva uno en la Iglesia de la Asunción de Cantillana, procedente de la iglesia de San Salvador de Carmona (Sevilla). Según Palomero ${ }^{25}$ es el modelo que seguirían los demás y la fuente para los que luego realizara Montañés. Aunque el citado autor relaciona esta tipología con el frontispicio de I Quatro Libri de Palladio, Venecia, 1570, pensamos que una mayor corrección y limpieza ostentan los modelos miguelangelescos abiertos en estampa y editados, entre otros por Lafreri, y que también fueron añadidos al ejemplar del Vignola conservado en el colegio de Arquitectos de Valencia, aunque estas estampas lo que hacen es reproducir edificios de Miguel Ángel.

Nos referimos, concretamente, a la estampa que aparece en el folio ( $88 \mathrm{r}$ ) de nuestro libro que reproduce el modelo de Miguel Ángel de la puerta de entrada a la Biblioteca Laurenziana de Florencia (Fig. 10), presentando varios elementos absolutamente definitivos para los retablos tabernáculo de Martínez Montañés del Convento de Santa Clara de Sevilla (Fig. 11). En primer lugar la solución del frontón recto roto ${ }^{26}$ al que se le introduce en el tímpano un elemento rectangular a manera de relieve, que será empleado por Montañés precisamente en los diferentes retablos de Santa Clara para las escenas alusivas del titular de cada retablo. Otro elemento clave para la asignación de esta fuente al ideario montañesino está en la forma quebrada en que termina la embocadura principal que daría cabida a la imagen titular y que en el grabado es la propia entrada de la puerta de la biblioteca Laurenziana.

Pero lo más llamativo es que en nuestro ejemplar del Vignola también hay un diseño prototipo para entender el Retablo-Tabernáculo (folio 38 r) (Fig. 12) en el que se muestra a una Virgen con el niño como asunto principal y en el ático, circunscrito en el rectángulo que se introduce en el tímpano de origen miguelangelesco, la figura de Dios Padre. Este dibujo, de una gran elegancia, si no es de Montañés, desde luego es de su círculo más inmediato y enteramente vinculable con los modelos del Convento de Santa Clara de Sevilla, por lo que ha de ser de fecha cercana a 1621-25.

Este conjunto de trazas, junto a las que no hemos podido identificar pero que indudablemente están en la órbita montañesina y que han de ser estudiadas por otros investigadores en el futuro, constituyen uno de los más preciados testimonios de la importancia que tuvo el dibujo arquitectónico en la Sevilla del primer tercio del xvir, y al mismo tiempo, son ejemplo vivo del proceso de trabajo del arquitecto retablista, que muestra una verdadera pasión por las láminas del Vignola, entre las que se encuentran, las fuentes de las que nacieron estos rasguños.

\footnotetext{
${ }^{25}$ Palomero Páramo, J., Opus cit., 1982, p. 509, fig. 18.

${ }^{26} \mathrm{La}$ idea de romper el frontón recto del ático lo pone en práctica por vez primera en 1572 Jerónimo Hernández en el retablo mayor de San Mateo de Lucena. Cfr. Palomero Páramo, J., Opus Cit., 1983, p. 96. Esta solución la debe de tomar igualmente del modelo miguelangelesco de la Biblioteca Laurenziana.
}

$A E A$, LXXVIII, 2005, 311, pp. 235 a 244 